\title{
Cardiac rehabilitation
}

\author{
Should be available to all who would benefit
}

Cardiac rehabilitation aims to restore patients with cardiac disease to their optimal physical, psychosocial, emotional, and vocational status. ${ }^{1}$ Coronary artery disease remains the main cause of premature disability in the United Kingdom, and patients who have suffered a myocardial infarction form the largest group considered for rehabilitation, although rehabilitation is equally important for patients who have undergone cardiac surgery ${ }^{2}$ or suffer from congestive heart failure. ${ }^{3}$ Nevertheless, fewer than half the health districts in the United Kingdom have established cardiac rehabilitation programmes. ${ }^{4}$

Cardiac rehabilitation programmes differ from centre to centre and in patients with different cardiac illnesses. In general, they consist of exercise, relaxation, and discussion. Patients join four to eight weeks after a myocardial infarction, although flexibility of timing of entry is desirable. Both light and heavy exercises have been shown to be of benefit in improving physical conditioning. ${ }^{5}$ Discussion sessions concentrate as necessary on patient education, risk factor modification, and individual counselling. Programmes are supervised by physiotherapists, nurses, or occupational therapists with doctors and other professionals available as necessary. They usually run for four to 12 weeks with one to six sessions a week. ${ }^{4}$

The availability of such programmes to cardiac patients seems justified in terms of cost:benefit. ${ }^{6}$ In the mid-1980s in the United Kingdom coronary artery disease was estimated annually to cost $£ 500 \mathrm{~m}$ in treatment and $£ 1800 \mathrm{~m}$ in lost production. ${ }^{7}$ It also accounted for $11.6 \%$ of sick leave. ${ }^{7}$ The running cost of a cardiac rehabilitation session is only $£ 4-£ 15$ per patient. ${ }^{4}$ The financial benefits gained in terms of productivity and maintaining an occupational income by returning to work are clear. In a Swedish study $51.8 \%$ of patients who had undergone cardiac rehabilitation remained in active employment five years after myocardial infarction compared with $27 \cdot 4 \%$ of a control group. ${ }^{8}$ This was due to reduced anxiety, depression, and recurrent cardiac events. The rate of readmission with cardiac disease, and hence the cost, was also lower in the patients who had been rehabilitated. This finding was supported by a recent American study, although in neither study were patients randomised.

Apart from reconditioning of patients, does cardiac rehabilitation reduce mortality and morbidity? Exercise promotes beneficial changes in the body. Heart rate and blood pressure are lowered at rest and at exercise. Increased high density lipoprotein cholesterol concentrations, ${ }^{10}$ improved glucose tolerance in diabetic patients, ${ }^{11}$ and enhanced fibrinolysis in response to thrombotic stimuli' ${ }^{12}$ have been documented, as have improvements in electrocardiographic ST segment changes, ${ }^{13}{ }^{14}$ ejection fraction, and ischaemic threshold. ${ }^{15}$ Among the randomised trials of exercise based rehabilitation after myocardial infarction performed in the 1970 s and 80 s only one reported a significant reduction in cardiac mortality, ${ }^{16}$ but some of these trials offered only short term follow up while others were small and vulnerable to type II statistical error. ${ }^{17}$

In the late 1980s two meta-analyses reported significantly lower pooled odd ratios for cardiovascular death $\left(0 \cdot 75^{18}\right.$ and $\left.0 \cdot 78^{19}\right)$. Overall mortality and cardiovascular mortality, defined as fatal reinfarction or sudden death, were reduced by $20 \%$ to $25 \%$ in patients randomised to an exercise programme. There was no significant difference in non-fatal reinfarction rates. Exercise based rehabilitation programmes therefore seem to have some prognostic value, perhaps in part due to risk factor modification, increased patient surveillance, and exercise training. Large clinical trials to confirm the conclusions of the meta-analyses are awaited.

Who should be eligible for cardiac rehabilitation programmes? In theory they should be available to all suitable patients, but the current lack of facilities precludes this. Patients who may benefit most include those who have multiple cardiac risk factors, a low exercise capacity, are slow to adjust psychologically to a new lifestyle, or have had recent cardiac surgery. Contraindications to exercise training include unstable angina pectoris, ventricular arrhythmias, and severe aortic stenosis.

Early mobilisation in patients who have had uncomplicated myocardial infarction and subsequent predischarge exercise testing are routine practice nowadays. The testing also serves to select patients suitable for rehabilitation (excluding those at extreme ends of the fitness spectrum) and in itself forms an important aspect of rehabilitation. Age is not an absolute contraindication, ${ }^{20}$ although there are obvious constraints in elderly patients. As the effects of training increase in an $S$ shaped curve and plateau in about $13-14$ weeks, ${ }^{21}$ patients leaving supervised programmes should continue long term exercise after adequate counselling. This also applies to low risk patients, who need not participate in formal programmes but can perform exercises at home with the help of rehabilitation manuals and audiotapes..$^{22}$

The cost of myocardial infarction and other cardiac illness is high and is in part the result of vocational disability. Against 
this background, it is reasonable to conclude that cardiac rehabilitation programmes are cost effective and should be made available to all who would benefit. In terms of their prognostic value, however, further research is needed.

T P CHUA Cardiology registrar DAVID P LIPKIN Consultant cardiologist

Department of Cardiology,

Royal Free Hospital,

London NW3 2QG

1 Hellerstein HK, Ford AB. Rehabilitation of the cardiac patient. $\{A M A$ 1957;164:225-31.

2 Tavazzi L, Boszormeny E, Broustet JP, Denolin H, Dorossiev D, Cobelli F, et al. Cardiac surgery: background and perspectives. Eur Heart f 1992;13(suppl C):35-40

Coats AJS, Adamopoulos S, Meyer TE, Conway J, Sleight P. Effects of physical training in chronic heart failure. Lancet 1990;355:63-6.

Horgan J, Bethell H, Carson P, Davidson C, Julian D, Mayou RA, Nagle R. Working Party Report on Cardiac Rehabilitation. Br Hean f 1992;67:412-8.

5 Goble AJ, Hare DL, Macdonald PS, Oliver RG, Reid MA, Worcester MC. Effect of early programmes of high and low intensity exercise on physical performance after transmural acute myocardial infarction. Br Hear f 1991;65:126-31.

Oldridge NB. Cardiac rehabilitation services: what are they and are they worth it? Comprehensive Therapy 1991;17:59-66.
7 Tunstall-Pedoe H. The health of the nation: responses. Coronary heart disease. BMF 1991;303: 701-4.

Levin LA, Perk J, Hedback B. Cardiac rehabilitation-cost analysis. f Int Med 1991;230:427-34

9 Ades PA, Huang D, Weaver MS. Cardiac rehabilitation participation predicts lower rehospitalisation costs. Am Hear f 1992;123:917-21.

10 Hartung GH, Squires WG, Gotto AM. Effect of exercise training on plasma high-density lipoprotein cholesterol in coronary disease patients. Am Heart f 1981;101:181-4.

11 Pedersen $\mathrm{O}$, Beck-Nielsen $\mathrm{H}$, Heding $\mathrm{L}$. Increase insulin receptors after exercise in patients with insulin-dependent diabetes mellitus. N Engl F Med 1980;302:886-92.

12 William RS, Logue EE, Lewis JL, Barton T, Stead NW, Wallace AG, Pizzo SV. Physical conditioning augments the fibrinolytic response to venous occlusion in healthy adults. $N$ Engl $\mathcal{f}$ Med 1980;302:987-91.

13 Detry JM, Bruce RA. Effects of physical training on exertional ST segment depression in coronary heart disease. Circulation 1971;4:390.

14 Todd IC, Ballantyne D. Effects of exercise training on the total ischaemic burden: an assessment by 24 hour ambulatory electrocardiographic monitoring. $\mathrm{Br}$ Heart f 1992;62:560-6.

15 Ehsani AA, Biello DR, Schultz J, Sobel BE, Holloszy JO. Improvement of left ventricular contractile function by exercise training in patients with coronary artery disease. Circulation 1986;74:350-8.

16 Kallio V, Hamalaiainen $\mathrm{H}$, Hakkila J, Luurila OJ. Reduction of sudden deaths by a multifactorial intervention program after myocardial infarction. Lancet 1979;ii: 1091-4.

17 Lipkin DP. Is cardiac rehabilitation necessary? Br Hear f 1991;65:237-8.

18 Oldridge NB, Guyatt GH, Fischer ME, Rimm AA. Cardiac rehabilitation after myocardia infarction. Combined experience of randomized clinical trials. $¥ A M A 1988 ; 260: 945-50$.
ind

19 O'Connor GT, Buring JE, Yusuf S, Goldhaber SZ, Olmstead EM, Paffenbarger RS, et al. An overview of randomized trials of rehabilitation with exercise after myocardial infarction Circulation 1989;80:234-44.

20 Siddiqui MA. Cardiac rehabilitation and elderly patients. Age Ageing 1992;21:157-9.

21 Al-Khawaja I. Benefits and risks of cardiac rehabilitation. Cardiology in Practice 1992;10:20-1.

22 Lewin B, Robertson IH, Cay EL, Irving JB, Campbell M. Effects of self-help post-myocardialinfarction rehabilitation on psychological adjustment and use of health services. Lance 1992;339:1036-40

\section{Designer hips}

\section{Don't let your patient become a fashion victim}

The number of total hip replacement operations performed in Britain is now starting to stabilise at about 40000 a year. ${ }^{1}$ The implants used to replace the hip are manufactured for this market by a dozen or so companies, many of which are multinationals with their main marketing base in the United States. The sales for each company in Britain are very small and commercially unimportant by manufacturing standards.

Until recently the profit margin has been tight, with an implant selling in Britain for less than half the price charged in the rest of Europe and the United States. A so called "rationalisation" of the market is now leading to the price charged in Britain rising at over twice the rate of inflation towards what is charged in other countries. ${ }^{2}$

A perfectly satisfactory standard total hip replacement could be marketed for not much over $£ 100$, but the price in Britain now varies from $£ 250$ to well over $£ 1000$ for each implant. The situation with knee replacements is similar but the margins, if anything, are even greater, with knee replacements costing around $£ 300$ to manufacture selling for between $£ 700$ and $£ 1500$. Many units have had to stop replacing joints again this year because they have run out of money-most unsatisfactory when cheaper hips are available and waiting lists are so long.

Budgets for prostheses have been used for years to limit elective orthopaedic activity because blocking the purchase of further implants stops joint replacement surgery, the "bread and butter" of current elective orthopaedic practice. The cost of the implant should be only a fraction of the total cost of surgery and inpatient care-overall cost $£ 3000-£ 5000$ per joint replacement (Nuffield Orthopaedic Centre NHS Trust costings, 1992). It is surprising how few units have changed to a cheaper implant in the face of a limiting budget for prostheses.

Why then do some units use expensive implants and risk closure when the money runs out? The answer is that the surgeons in those units believe that the expensive implants are better than the cheaper models. They are encouraged in this by the manufacturing companies, which scarcely let a year go by without introducing a "new improved" joint replacement which offers hitherto undreamt of (and unproved) advantages over the older designs.

The cost of the new designs includes development, tooling, advertising, and marketing and is contributing (the manufacturers claim) to the rapid rise in the cost of implants in Britain. The implant has to be manufactured in many different sizes, and in Britain often fewer than 200 are sold in each size before the design becomes obsolete (S M Hamilton, personal communication). Development costs have to be recouped rapidly if the company is to make a profit and introduce an even newer hip next year.

The long term clinical results (over 10 years) obtained with some implants (some of the cheapest on the market today) are very good, with failure rates of less than $1 \%$ a year. ${ }^{3}$ Frequently, the newer and more expensive designs prove, after a few years of use (and a few hundred hapless patients), to give results substantially worse than this and are quietly withdrawn from the market despite initial optimism over their theoretical advantages. In Sweden the Christiansen hip was used in over 5000 total hip replacement operations before its high failure rate was appreciated. If a more reliable hip replacement had been used it is estimated that the Swedish community would have saved $\$ 20 \mathrm{~m}$, never mind the human suffering. ${ }^{4}$

If every surgeon in Britain used the most reliable prosthesis and achieved the same results as the best units the annual cost of revision operations would be $£ 200 \mathrm{~m}$. If less reliable prostheses or techniques were used the cost at 10 years would be over three times as much. ${ }^{5}$ This "fashion trade" in joint replacements is costing the health service many millions of pounds each year and, even more important, is causing patients unnecessary pain and distress through early failure of unproved implants.

Currently the need for a revision is the most commonly 